\title{
Pattern of nucleotide variants of TP53 and their correlation with the expression of p53 and its downstream proteins in a Sri Lankan cohort of breast and colorectal cancer patients
}

Vahinipriya Manoharan ${ }^{1}$, Eric Hamilton Karunanayake', Kamani Hemamala Tennekoon', Sumadee De Silva ${ }^{1 *}$ (D), Ahamed Ilyas Ahamed Imthikab ${ }^{1}$, Kanishka De Silva ${ }^{2}$, Preethika Angunawela ${ }^{3}$, Sameera Vishwakula ${ }^{4}$ and John Lunec ${ }^{5}$

\begin{abstract}
Background: Breast cancer (BC) is known to be the most common malignancy in females whereas colorectal cancer (CRC) incidence also higher in both genders in Sri Lanka. TP53 is an important tumour suppressor gene and its somatic mutations are reported in approximately 27\% of BC and 43\% of CRC cases. Analysis of TP53 gene variants not only provides clues for the aetiology of the tumour formation, but also has an impact on treatment efficacy. The current study was conducted to investigate the pattern of TP53 variants in patients with BC and CRC from Sri Lanka.

Methods: 30 patients with BC, 21 patients with CRC and an equal number of healthy controls were screened for mutational status of TP53 by polymerase chain reaction (PCR) followed by direct sequencing. In addition, a subset of these samples were analysed for the protein expression of p53 and comparison made with the mutational status of TP53. We also analysed the protein expression of p21 and MDM2 as potential indicators of p53 functional status and compared it with the protein expression of p53. Additionally, hotspot codons of the KRAS, BRAF and PIK3CA genes were also analysed in a subset of CRC patients.
\end{abstract}

Results: Twenty seven sequence variants, including several novel variants in the TP53 gene were found. Nine BC and seven CRC tumour samples carried pathogenic TP53 variants. Pathogenic point missense variants were associated with strong and diffuse positive staining for p53 by immunohistochemistry $(\mathrm{IHC})$, whereas, wild type TP53 showed complete absence of positive IHC staining or rare positive cells, regardless of the type of cancer. There was no direct correlation between p21 or MDM2 expression and p53 expression in either BCs or CRCs. Four of the CRC patients had pathogenic hotspot variants in KRAS; three of them were on codon 12 and one was on codon 61.

Conclusion: The prevalence of pathogenic somatic TP53 variants was 31 and $33.33 \%$ in the studied BC and CRC cohorts respectively. All of them were located in exons 5-8 and the pathogenic missense variants were associated with strong immuno-positive staining for p53.

Keywords: Breast cancer, Colorectal cancer, Sri Lanka, TP53, Genetic variation, Immunohistochemistry

\footnotetext{
*Correspondence: sum@ibmbb.cmb.ac.lk

'Institute of Biochemistry Molecular Biology and Biotechnology, University of

Colombo, 90, Cumaratunga Munidasa Mawatha, Colombo 3, Sri Lanka

Full list of author information is available at the end of the article
}

(c) The Author(s). 2020 Open Access This article is distributed under the terms of the Creative Commons Attribution 4.0 International License (http://creativecommons.org/licenses/by/4.0/), which permits unrestricted use, distribution, and reproduction in any medium, provided you give appropriate credit to the original author(s) and the source, provide a link to the Creative Commons license, and indicate if changes were made. The Creative Commons Public Domain Dedication waiver (http://creativecommons.org/publicdomain/zero/1.0/) applies to the data made available in this article, unless otherwise stated. 


\section{Background}

$\mathrm{BC}$ and $\mathrm{CRC}$ are commonly diagnosed malignancies worldwide [1, 2]. According to cancer incidence data, 2014 by the National Cancer Control Programme, BC is the leading cancer among Sri Lankan women accounting for $25.2 \%$ of total cancers and CRC ranks fourth (6.9\%) and fifth (7.3\%) in males and females respectively [3]. Early menarche, late menopause, being nulliparous, lack of breast feeding, use of oral contraceptives, and a family history of $\mathrm{BC}$ or other cancers are some of the major risk factors associated with $\mathrm{BC}$ [4] while risk factors for CRCs include age, obesity, dietary factors, smoking, alcoholism and personal history of adenomatous polyps/inflammatory bowel diseases [5].

TP53, a tumour suppressor gene is one of the key factors involved in tumour development, progression and prognosis. Somatic mutations in the TP53 gene are reported in approximately $26.51 \%$ of $\mathrm{BC}$ and $43.32 \%$ of CRC cases $[1,6]$. The TP53 gene contains 11 exons and 10 introns and is located on the short arm of chromosome 17. The p53 protein is a phosphoprotein of 393 amino acid $(55 \mathrm{kDa})$ which includes an amino-terminal acidic transcription activation domain (1-67), a proline rich region (67-98), a core DNA binding domain (98$303)$, a nuclear localization signal-containing region (303-323), an oligomerisation domain (323-363) and a C-terminal basic domain (363-393). It acts as a transcription factor for several target genes. The CDKN1A gene, major transcriptional target of $\mathrm{p} 53$, codes for the p21 cyclin-dependent kinase inhibitory protein which causes cell cycle arrest. $M D M 2$ is another important transcriptional target gene of p53, where the MDM2 protein controls the level of p53 by a negative autoregulatory feedback loop in which MDM2 binds to and ubiquitinates p53, targeting it for proteasomal degradation [7].

According to the COSMIC database, more than 50\% of the TP53 alterations are missense mutations. This is followed by non-sense mutations contributing to about $10 \%$ of total TP53 alterations [6]. The functional status of p53 has an impact on treatment efficacy [8]. Thus, recognition of the functional status of p53 may benefit in the selection of treatment option and prognostication of treatment efficacy. Identification of hotspot regions of TP53 variants is useful to prioritize screening of such regions prior to treatment in a resource limited setting such as Sri Lanka.

Most research on p53 including trends of incidence, genetic analysis and treatment response have been carried out in developed countries, while analysis of such trends and patterns in developing countries including Sri Lanka are limited. Since the types of TP53 alterations and their frequencies have been suggested to be influenced by geographical factors and ethnicity, the current study intended to establish the mutation spectrum of TP53 in Sri Lankan BC and CRC patients [9, 10]. This is the first report on TP53 alterations in Sri Lankan patients with sporadic $\mathrm{BC}$ and CRC.

In addition, association of $\mathrm{BCs}$ with $\mathrm{CRCs}$ is controversial, as some studies have suggested that $\mathrm{BC}$ survivors are at a higher risk of developing CRC due to risk factors such as obesity and the level of exogenous and endogenous sex hormones $[11,12]$ while other studies have proposed that there are no such associations [13]. In this study, we compared the mutation spectrum of TP53 among BCs and CRCs to evaluate their genetic basis.

Furthermore, immunohistochemistry (IHC) was carried out to measure the protein expression of p53 and to correlate the immuno-detection of p53 with the mutational status of TP53 gene. We also studied the expression of p53 downstream targets and compared those with the immune-detection of p53.

\section{Methods \\ Recruitment of the participants for the study and processing of the samples}

Ethical clearance $(\mathrm{EC} / 14 / 160)$ was granted by the Ethics Review Committee of the Faculty of Medicine, University of Colombo, Sri Lanka. A total of 92 participants were recruited, which includes 30 patients with $\mathrm{BC}, 21$ patients with CRC and 41 healthy controls (30 females, 11 males) without any personal or family history of cancer.

Prior to the recruitment, the study was explained and written informed consent was obtained from the patients and healthy controls. Clinical and socio- demographic data of the participants were collected via medical reports and questionnaires respectively.

One part of the surgically excised tumor tissues was placed in 10\% formalin to make Formalin Fixed Paraffin Embedded (FFPE) blocks, while the other part was placed immediately in Allprotect ${ }^{\circ}$ Tissue Reagent (QIAGEN, cat no. 76405, Hilden, Germany) and stored at$20^{\circ} \mathrm{C}$ until processed.

Genomic DNA extraction from the excised tumour piece of patients and from blood of healthy controls was carried out as in Manoharan et al., 2019 [14]. PCR amplification of TP53 exon and flanking genomic DNA sequences was performed. The nucleotide sequence of PCR primers used and reaction conditions have been previously reported [14]. Wizard ${ }^{\circ} \mathrm{SV}$ Gel and PCR Clean-Up kit (Promega) was used to purify the PCR products. Direct sequencing was carried out for purified products using the BigDye ${ }^{\bullet}$ Terminator v3.1 kit (Thermo Fisher Scientific, Waltham, MA USA) and an Applied Biosystems ${ }^{\mathrm{Tm}}$ 3500Dx Genetic Analyzer (ThermoFisher Scientific).

The sequencing results were analyzed through BioEdit ${ }^{\circ}$ software by aligning with the Human NCBI TP53 
reference sequence (Genbank accession number - $\mathrm{NC}_{-}$ 000017) and confirmed further using Mutation Surveyor ${ }^{\circ}$ V4.0.9 and Alamut ${ }^{\circ}$ Visual 2.7.2 Documentation. Guidelines of the Human Genome Variation Society (HGVS) nomenclature (http:/www.hgvs.org/mutnomen/) were used to name the identified sequence variants.

\section{Analysis of sequence variants}

The following databases were used to check the identified sequence variants for previous reporting: Catalogue Of Somatic Mutations in Cancer (COSMIC) (http://cancer.sanger.ac.uk/cosmic); NCBI (https://www.ncbi.nlm. nih.gov/); IARC TP53 (http://p53.iarc.fr/); Ensembl (https://asia.ensembl.org/index.html); the p53 website (https://p53.fr/tp53-database).

Pathogenicity of exonic variants was analysed using comparative programs of missense prediction; Align GVGD (http://agvgd.hci.utah.edu/agvgd_input.php); SIFT (http://sift.jcvi.org/www/SIFT_seq_submit2.html); MutationTaster (http://www.mutationtaster.org/); PolyPhen-2 (http://genetics.bwh.harvard.edu/pph2/); Provean (http:// provean.jcvi.org/seq_submit.php). Gene splicing was assessed using Human Splicing Finder V3.0 (http://www. umd.be/HSF3/) and splicing window of Alamut Visual software. Data on structural and functional activity of the p53 available on IARC TP53 database such as transcriptional activity and Dominant Negative Effect was also considered for pathogenicity determination of the exonic variants identified [15]. Classification of all variants was done according to the standards and guidelines of American College of Medical Genetics [16].

Structure based activity prediction for the novel exonic variants was done using protein structure comparison software TM align (https://zhanglab.ccmb.med.umich. edu/TM-align/). The X-ray diffraction structure of wild type p53 protein complexed with DNA (PDB ID 1TUP) was used to identify the structural position of variant sequences. The structure of the protein with novel variants was built using SWISS-MODEL (https:// swissmodel.expasy.org/).

\section{Immuno expression of p53, p21 and MDM2}

IHC characterization was performed on representative FFPE tumour sections of thirteen BC and fourteen CRC cases randomly selected, to evaluate the immuno expression of p53, p21, and MDM2. The commercially available primary antibodies used were mouse monoclonal Anti-Human p53 clone DO-7 (Agilent DaKo, Santa Clara, USA), Rabbit monoclonal p21 Waf1/Cip1 2947S (Cell signalling technology, Danvers, MA, USA) and mouse monoclonal Anti-MDM2 OP46 (MerkMillipore, Massachusetts, USA) for detecting of p53, p21 and MDM2 respectively. Trials were performed to optimise the concentration, incubation time of the primary antibodies and antigen retrieval buffer (Citrate, $\mathrm{pH}=6$ and Tris, $\mathrm{pH}=9$ ). The best outcomes were used for the samples and the optimised conditions are tabulated in Additional file 1: Table S1. The paraffin-embedded pellets of MDM2 inhibitor treated (5 $\mu \mathrm{M}$ Nutlin-3) MCF7 cells was used as a positive control for p53 and p21 antibodies and paraffin-embedded pellets of MDM2 inhibitor treated $(10 \mu \mathrm{M}$ Nutlin-3) SJSA cells was used as a positive control for the MDM2 antibody. The general IHC conditions have been previously reported [14]. AperioScanScope $^{\circ}$ CS System (Aperio Technologies, Bristol, UK) and Spectrum ${ }^{\mathrm{Tm}}$ image management software were used to visualize the images of the IHC stained slides and the images were finally analysed as described in Manoharan et al., 2019 [14].

\section{Analysis of hotspot regions of KRAS, BRAF and PIK3CA}

PCR specific primers were designed to amplify the hotspot regions of KRAS (Codon 12, 13, 61 and 146), BRAF (codon 600) and PIK3CA (codon 1047). 17 CRC samples were subjected to PCR amplification followed by direct sequencing. The results obtained were analysed in the same manner as for TP53.

\section{Statistical analysis}

The Pearson's chi-squared test and Spearman's Rank Correlation tests were done to find the strength and the direction of the associations. A $p$-value $<0.05$ was considered as statistically significant at $5 \%$ level.

\section{Results}

Baseline characteristics of the study participants

Mean $( \pm$ SD) age of the studied patient cohort was 59.24 $( \pm 10.16)$ years for BC and $60.29( \pm 11.45)$ for CRC, 48.9 $( \pm 13.91)$ for healthy female controls and $49.01( \pm 17.14)$ for healthy male controls. The baseline characteristics of the $\mathrm{BC}$ and CRC patients are summarized in Tables 1 and 2 respectively. The majority of both $\mathrm{BC}$ and CRC patient population represents the Sinhalese ethnicity and were over 40 years in age.

\section{Analysis of TP53 sequence variants}

A total of 16 sequence variants were found in $30 \mathrm{BC}$ patients and 15 sequence variants were found in $21 \mathrm{CRC}$ patients. In healthy male and female controls 6 and 8 variants were found respectively. Table 3 illustrates the characteristics of each variant and detailed in-silico and functional analysis are given in Additional file 2: Table S2.

Two novel frameshift variants were found in exon 8 . The first of these, c.848_849delGC (Fig. 1), was observed in a 55 year old female BC patient with triple negative, poorly differentiated invasive ductal carcinoma, which results in an Arginine to Histidine substitution at the site of the deletion followed by other downstream amino 
Table 1 Clinicopathological characteristics of breast cancer patients and healthy controls

\begin{tabular}{|c|c|c|c|c|}
\hline Characteristics & $\begin{array}{l}\text { Total Number of } \\
\text { patients }\end{array}$ & $\begin{array}{l}\text { Number of patients with Wild type } \\
\text { TP53 }\end{array}$ & $\begin{array}{l}\text { Number of patients with mutated } \\
\text { TP53 }\end{array}$ & $\begin{array}{l}\text { Number of healthy } \\
\text { controls }\end{array}$ \\
\hline \multicolumn{5}{|l|}{ Ethnicity } \\
\hline Sinhalese & 25 & 18 & 7 & 24 \\
\hline Tamil & 1 & 1 & 0 & 5 \\
\hline Muslims & 2 & 2 & 0 & 0 \\
\hline Burgher & 2 & 0 & 2 & 1 \\
\hline \multicolumn{5}{|l|}{ Age at study entry } \\
\hline$<40$ years & 1 & 1 & 0 & 9 \\
\hline 40-60 years & 14 & 11 & 3 & 13 \\
\hline$>61$ years & 15 & 10 & 5 & 8 \\
\hline \multicolumn{5}{|l|}{ Body Mass Index } \\
\hline Underweight & 2 & 2 & 0 & 2 \\
\hline Ideal & 9 & 7 & 2 & 9 \\
\hline Overweight & 5 & 4 & 1 & 4 \\
\hline Pre obese & 10 & 6 & 4 & 11 \\
\hline Obese & 4 & 2 & 2 & 4 \\
\hline \multicolumn{5}{|l|}{ Tumour type } \\
\hline $\begin{array}{l}\text { Invasive Ductal } \\
\text { Carcinoma }\end{array}$ & 29 & 20 & 9 & N/A \\
\hline $\begin{array}{l}\text { Invasive Lobular } \\
\text { Carcinoma }\end{array}$ & 1 & 1 & 0 & N/A \\
\hline \multicolumn{5}{|l|}{ Breast affected } \\
\hline Left & 11 & 7 & 4 & N/A \\
\hline Right & 17 & 13 & 4 & N/A \\
\hline both & 2 & 1 & 1 & N/A \\
\hline \multicolumn{5}{|l|}{ Menstrual status } \\
\hline Pre menopausal & 7 & 5 & 2 & 19 \\
\hline Post menopausal & 23 & 16 & 7 & 11 \\
\hline \multicolumn{5}{|l|}{ Pregnancy history } \\
\hline Nulliparous & 7 & 4 & 3 & 9 \\
\hline $1-3$ children & 21 & 16 & 5 & 20 \\
\hline$>3$ children & 2 & 1 & 1 & 1 \\
\hline \multicolumn{5}{|c|}{ Breast Feeding history (Total) } \\
\hline No breast feeding & 7 & 4 & 3 & 9 \\
\hline$<=$ one year & 4 & 3 & 1 & 8 \\
\hline > one year & 18 & 13 & 5 & 13 \\
\hline \multicolumn{5}{|l|}{ History of cancer } \\
\hline Previous history & 6 & 3 & 3 & N/A \\
\hline Family history & 11 & 8 & 3 & N/A \\
\hline \multicolumn{5}{|c|}{ Codon 72 polymorphism } \\
\hline Arginine & 12 & 10 & 2 & 12 \\
\hline Proline & 7 & 2 & 5 & 5 \\
\hline Arginine/ Proline & 11 & 9 & 2 & 13 \\
\hline
\end{tabular}


Table 2 Baseline characteristics of colorectal cancer patients and healthy controls

\begin{tabular}{|c|c|c|c|c|}
\hline Characteristics & $\begin{array}{l}\text { Total Number of } \\
\text { patients }\end{array}$ & $\begin{array}{l}\text { Number of patients with Wild } \\
\text { type TP53 }\end{array}$ & $\begin{array}{l}\text { Number of patients with } \\
\text { mutated TP53 }\end{array}$ & $\begin{array}{l}\text { Number of healthy } \\
\text { controls }\end{array}$ \\
\hline \multicolumn{5}{|l|}{ Sex } \\
\hline Male & 14 & 12 & 2 & 11 \\
\hline Female & 7 & 2 & 5 & 10 \\
\hline \multicolumn{5}{|l|}{ Ethnicity } \\
\hline Sinhalese & 19 & 12 & 7 & 17 \\
\hline Tamil & 1 & 1 & 0 & 4 \\
\hline Muslims & 1 & 1 & 0 & 0 \\
\hline \multicolumn{5}{|l|}{ Age at study entry } \\
\hline $30-60$ years & 9 & 7 & 2 & 16 \\
\hline$>60$ years & 12 & 7 & 5 & 5 \\
\hline \multicolumn{5}{|l|}{ Body Mass index } \\
\hline Under weight & 2 & 2 & 0 & 1 \\
\hline Ideal Weight & 11 & 5 & 5 & 8 \\
\hline Overweight & 6 & 4 & 2 & 7 \\
\hline Pre obese & 2 & 2 & 0 & 3 \\
\hline Obese & 0 & 0 & 0 & 2 \\
\hline \multicolumn{5}{|l|}{ Histological status of cancer } \\
\hline $\begin{array}{l}\text { Well differentiated } \\
\text { adenocarcinoma }\end{array}$ & 3 & 2 & 1 & N/A \\
\hline $\begin{array}{l}\text { Moderately differentiated } \\
\text { adenocarcinoma }\end{array}$ & 10 & 6 & 4 & N/A \\
\hline $\begin{array}{l}\text { Poorly differentiated } \\
\text { adenocarcinoma }\end{array}$ & 1 & 1 & 0 & N/A \\
\hline Unknown & 7 & 5 & 2 & N/A \\
\hline \multicolumn{5}{|l|}{ Smoking history } \\
\hline Yes & 6 & 6 & 0 & 3 \\
\hline No & 15 & 8 & 7 & 18 \\
\hline \multicolumn{5}{|l|}{ Alcohol consumption } \\
\hline Yes & 9 & 8 & 1 & 6 \\
\hline No & 12 & 6 & 6 & 15 \\
\hline \multicolumn{5}{|l|}{ Betel-quid chewing } \\
\hline Yes & 10 & 8 & 2 & 3 \\
\hline No & 11 & 6 & 5 & 18 \\
\hline \multicolumn{5}{|l|}{ Codon 72 polymorphism } \\
\hline Arginine & 6 & 5 & 1 & 6 \\
\hline Proline & 6 & 3 & 3 & 5 \\
\hline Arginine/ Proline & 9 & 6 & 3 & 10 \\
\hline
\end{tabular}

acid changes and truncation of the protein at codon 303. The second frameshift variant, c.851_855delCAGAG (Fig. 1), was found in a 62 year old female BC patient with human epidermal growth factor receptor-2 (HER2) negative invasive ductal carcinoma with Ki67 index 32\% and it result in a coding change from Threonine to Arginine at the site of deletion and other downstream amino acid encoding changes, plus a premature stop codon at position 302. Both the predicted truncated proteins are similar in length, with tetramerization and negative regulatory domains lost in both proteins.

A novel 3-base pair in-frame deletion was identified in exon 5. c.431_433delAGC (Fig. 2), resulting in the loss of the Glutamine amino acid residue at position 144 present in the $\beta$ strand of the DNA binding domain and produces a 392 amino acid, shorter by one amino acid 


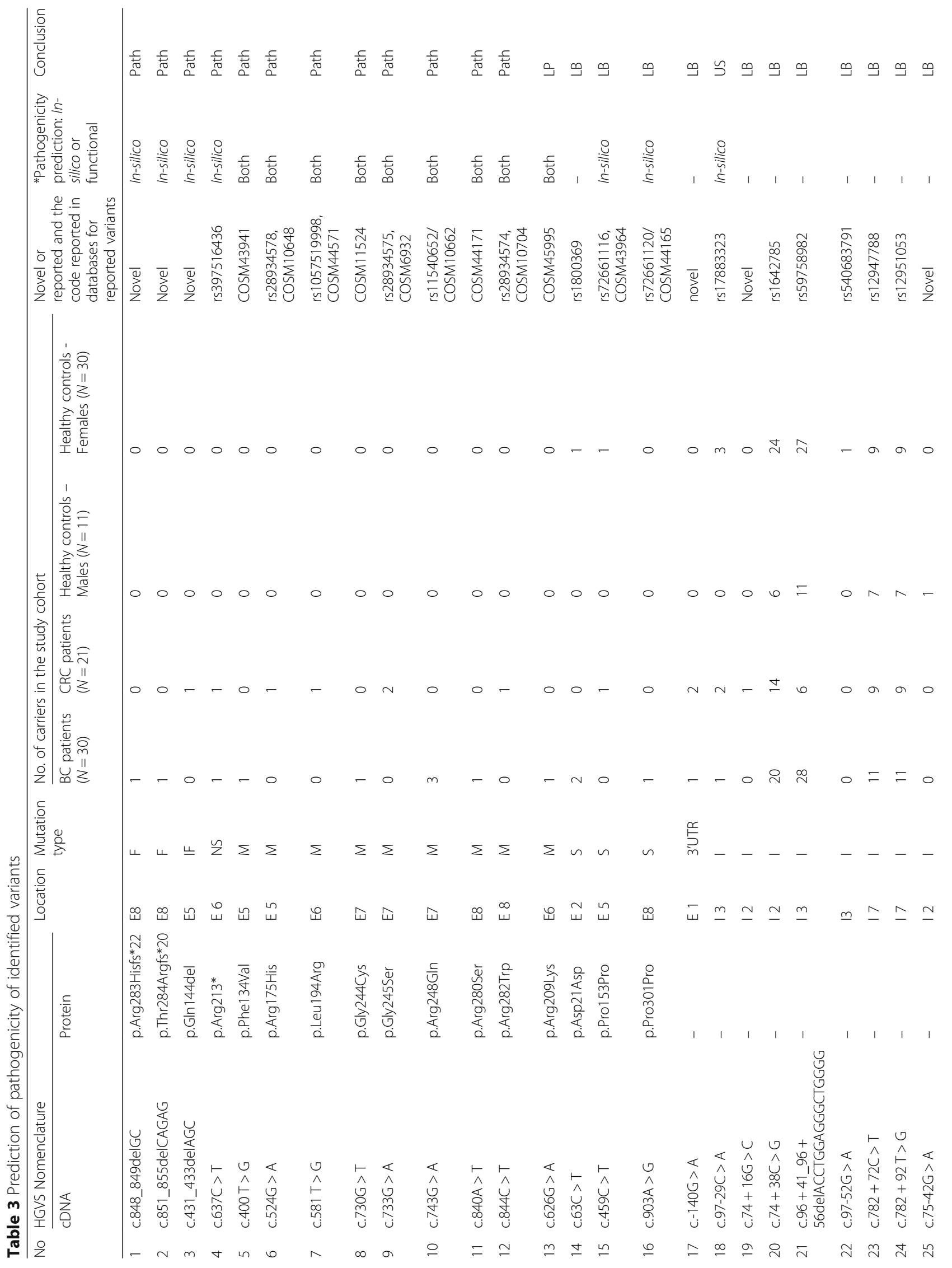




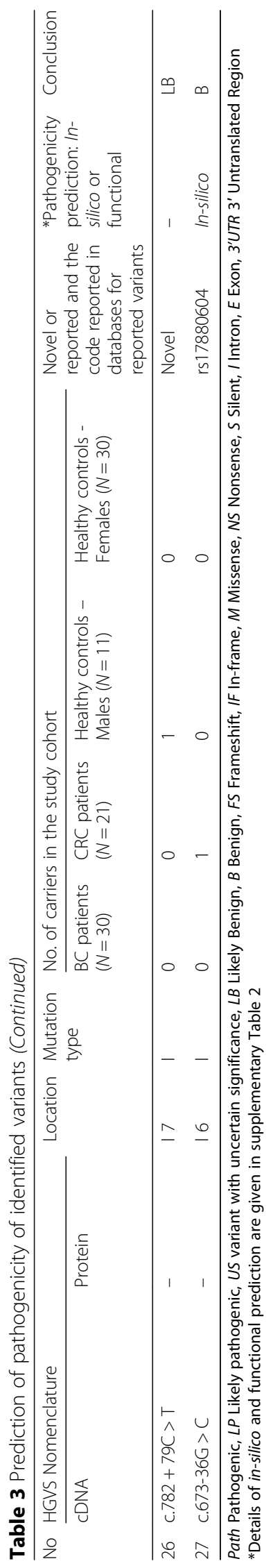




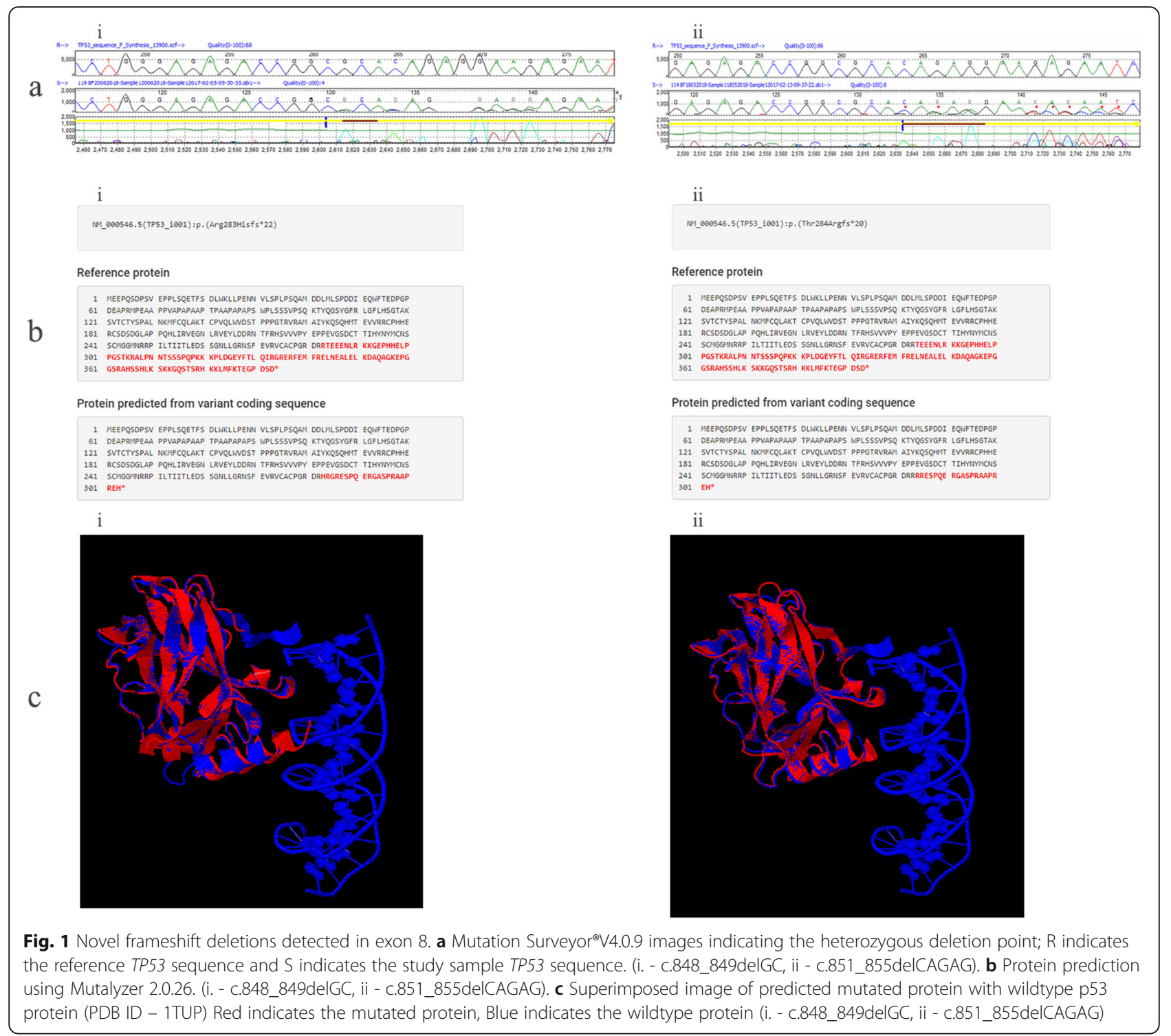

compared with the 393 amino acid full length protein. It was detected in a 66-year-old female CRC patient with moderately differentiated adenocarcinoma who had a previous history of cervix cancer. This patient also had a pathogenic KRAS codon 12 variant sequence (c.35G > A; rs121913529).

A reported nonsense variant, c. $637 \mathrm{C}>\mathrm{T}$ in exon 6 was found in both BC and CRC patients, resulting in a change from Arginine to a stop codon at 213. This truncated protein lacks part of the DNA binding domain, the tetramerization domain and negative regulatory domain, which would make the p53 protein nonfunctional. The BC patient was 47 years old with estrogen receptor (ER)/ progesterone receptor (PR) positive, HER2 equivocal invasive ductal carcinoma. The CRC patient was a 58 year old female with moderately differentiated adenocarcinoma.
There were four reported pathogenic missense variants, c.400 T > G, c.730G > T, c.743G $>$ A, c.840A $>$ T in exons 5,7 and 8 observed only in $\mathrm{BC}$ patients. Variants c. $400 \mathrm{~T}>\mathrm{G}, \mathrm{c} .730 \mathrm{G}>\mathrm{T}$ and c.840A $>\mathrm{T}$ were observed in one patient each, while c.743G $>$ A present in a CpG site was observed in 3 patients and 2 of them had triple negative invasive ductal carcinoma.

There were four reported pathogenic missense variants, c. $524 \mathrm{G}>\mathrm{A}$, c. $581 \mathrm{~T}>\mathrm{G}, \mathrm{c} .733 \mathrm{G}>\mathrm{A}, \mathrm{c} .844 \mathrm{C}>\mathrm{T}$ in exon $5,6,7$ and 8 respectively observed only in patients with CRC. A c.524G > A variant was observed in a 67 year old male patient with moderately differentiated adenocarcinoma. He also had the pathogenic KRAS codon 61 variant (c.183A > T; rs17851045). A c.581 T > $G$ substitution was found in a 65 year old female with well differentiated adenocarcinoma. The missense variant c.733G > A was found in a 62 year old male patient 


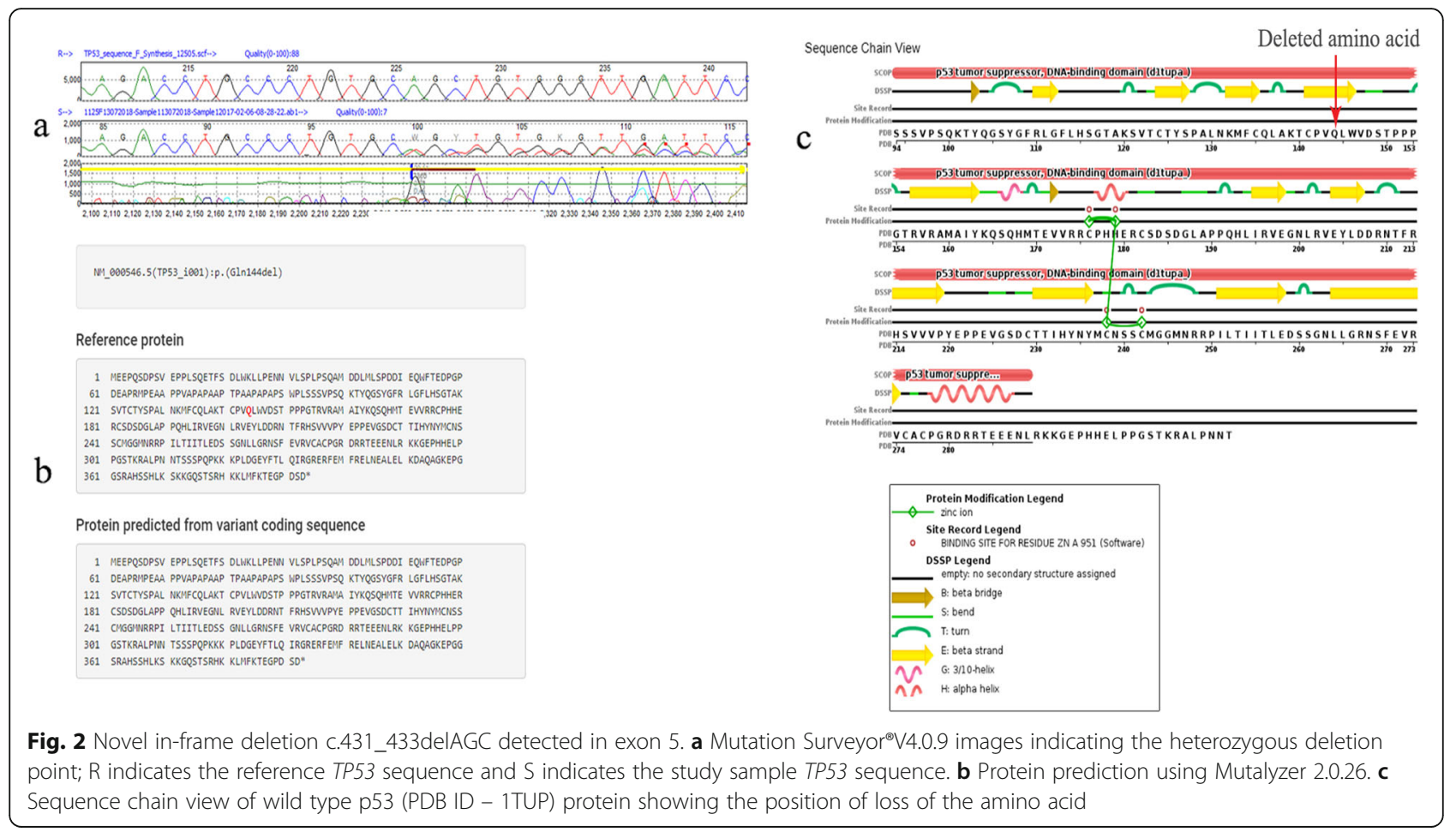

with moderately differentiated adenocarcinoma and in a 71 year old female with tubular adenocarcinoma. A c.844C $>\mathrm{T}$ substitution was reported in a 66 year old female with moderately differentiated adenocarcinoma, who had a previous history of ovarian cancer. She also carried the pathogenic KRAS codon 12 variant (c.34G > C; rs121913530).

A likely pathogenic variant c.626G > A in exon 6 was observed in a 48 year old BC patient with ductal carcinoma. There were also 2 silent variants with uncertain significance, of which, c.63C $>\mathrm{T}$ appeared in $2 \mathrm{BC}$ patients and in 1 female healthy control and c.459C $>\mathrm{T}$ appeared in 1 CRC patient and in a healthy control. Another silent variant c.903A $>\mathrm{G}$ observed in exon 8 in $1 \mathrm{BC}$ patient is categorized as likely benign.

The codon 72 variant (p.R72P) in exon 4 is a well known TP53 polymorphism. In the present study, R/R, $\mathrm{R} / \mathrm{P}$ and $\mathrm{P} / \mathrm{P}$ genotype distribution was $12(40 \%), 11$ (36.67\%), 7 (23.33\%) respectively in BC patients and 12 (40\%), 13 (43.33\%) and 5 (16.66\%) respectively in healthy controls. No significant difference was observed $(p=$ 0.78 ) in the prevalence of different genotypes in either the $\mathrm{BC}$ patients or the healthy controls. The genotypic distribution of $\mathrm{R} / \mathrm{R}, \mathrm{R} / \mathrm{P}$ and $\mathrm{P} / \mathrm{P}$ was 6 (28.57\%), 9 (42.86\%), 6 (28.57\%) respectively in CRC patients and 6 (28.57\%), $10(47.62 \%)$ and $5(23.81 \%)$ respectively in healthy controls. Similarly, there was also no significant difference ( $p$ value $=0.93$ ) observed in the prevalence of different genotypes between the CRC patients and healthy controls.

\section{Immunohistochemistry}

The results obtained from immunohistochemistry analysis of $13 \mathrm{BC}$ and $14 \mathrm{CRC}$ tissue samples for IHC, were categorized into three; widespread IHC positive tumour nuclear staining involving either the entire or a segment of a tissue section (Pattern-A), rare/ scattered positive cells (Pattern-B) and complete absence of IHC positive signal (Pattern-C) (Fig. 3).

\section{Status of TP53 gene and the p53 protein expression}

For BC patients, positive IHC staining was detected in $7 / 13(53.85 \%)$ cases. Three of these tumour sections showed pattern A, while 4 showed Pattern-B. All 3 BC cases that showed Pattern-A had TP53 missense variants while the 4 cases that showed PatternB had no detectable pathogenic variants of TP53. Among the 6 cases with immuno-negativity (Pattern$\mathrm{C})$, one had a silent variant and the remaining 5 patients had wild-type TP53.

For CRC patients, positive IHC staining was observed in $11 / 14(78.57 \%)$ cases. Four of these tumours showed pattern A, while 7 showed pattern-B. Among the 4 CRC samples that showed pattern A, 3 had a TP53 missense variant each, while the remaining case had no detectable pathogenic variants. All 7 cases that showed pattern-B had no detectable pathogenic TP53 variants. Among the 3 cases with pattern- $C$, one had a non-sense variant, another one had a silent variant and the remaining patient showing immuno-negativity had wild-type TP53. 


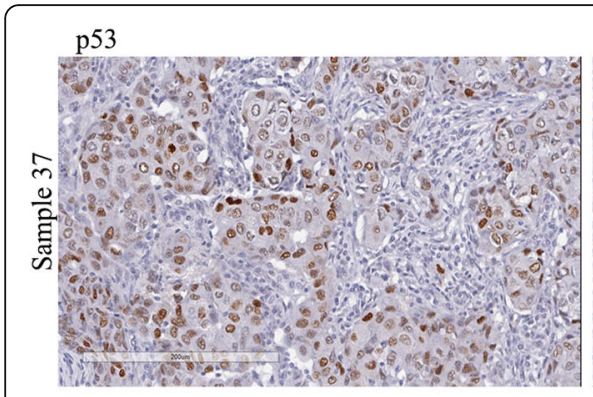

p53

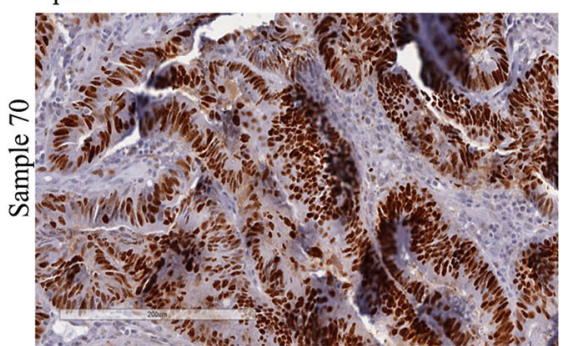

p21

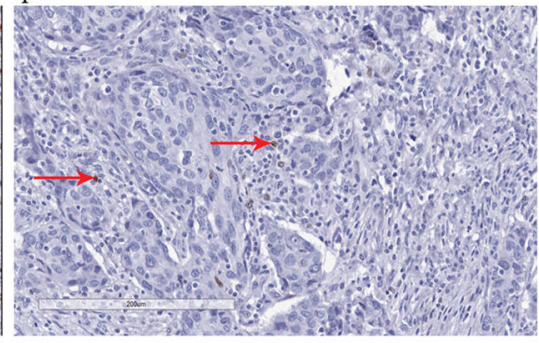

p21

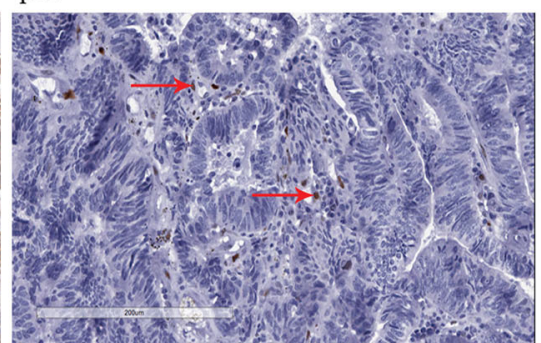

MDM2

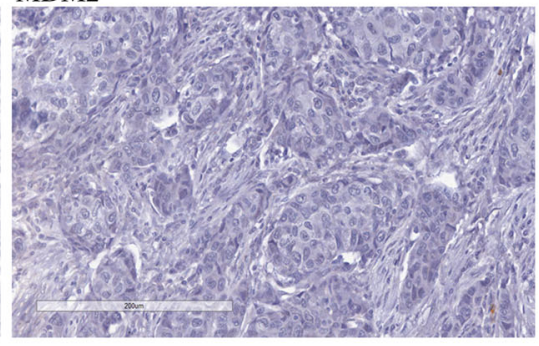

MDM2

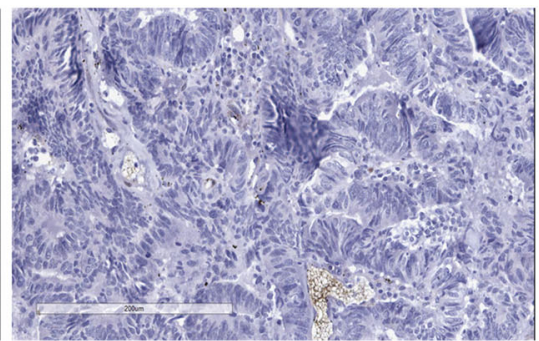

Fig. 3 Different pattern of nuclear immunohistochemical expression of p53, p21 and MDM2 in a breast cancer tissue (Sample 37) and $\mathbf{b}$ colorectal cancer tissue (Sample 70) (Magnification 20X). p53 shows pattern A, p21 shows pattern B (red arrows indicate the rare positive cells) and MDM2 shows pattern c staining

\section{Comparison of p53 protein expression with the expression p21 and MDM2}

Among the $3 \mathrm{BC}$ samples showing p53 IHC staining with pattern A; 1 showed pattern $B$ staining and the remaining 2 showed pattern $C$ for $p 21$. From the 4 samples with pattern $B$ of $\mathrm{p} 53$ expression, 3 showed pattern $\mathrm{B}$, while 1 showed pattern $\mathrm{C}$ for $\mathrm{p} 21$. All 6 samples with pattern C IHC for p53 also showed pattern C for $\mathrm{p} 21$. However, expression of MDM2 for all samples showed pattern $\mathrm{C}$ IHC staining, regardless of the expression pattern of p53 or p21 protein (Table 4-1).

Among 4 CRC samples with pattern A p53 IHC staining, 2 showed pattern $B$ and the remaining 2 showed pattern $C$ staining for $\mathrm{p} 21$. All 7 samples with pattern $B$ p53 IHC staining showed pattern B staining for p21. Among 3 with pattern $\mathrm{C}$ p53 IHC staining, 2 showed pattern $\mathrm{C}$ staining for $\mathrm{p} 21$ and the remaining one showed pattern A for p21 IHC staining. In the case of MDM2, among the 4 samples with p53 IHC staining with pattern A, 1 showed pattern $\mathrm{B}$ and the remaining 3 showed pattern C. From the 7 samples with pattern B of p53 expression, 4 showed pattern $B$, while 3 showed pattern $\mathrm{C}$ for MDM2. All 3 samples with pattern $\mathrm{C}$ IHC for p53 also showed pattern C for MDM2 (Table 4-2).

\section{Discussion}

This is a preliminary study focused on the mutation spectrum of the TP53 gene and expression of p53 and downstream p53 transcriptional proteins for a series of Sri Lankan BC and CRC patients.
Invasive ductal and lobular BCs are the major malignancies of the breast and account for approximately 80 and $15 \%$ of cases respectively [17]. In our study cohort, $96.5 \%$ were ductal carcinoma and only $3.5 \%$ were the lobular carcinoma. The frequency of pathogenic TP53 variation in the $\mathrm{BC}$ patient cohort $(31 \%)$ was closer to figures reported in the cBioportal and IARC TP53 databases (32 and 22.8\% respectively). But the frequency of pathogenic TP53 variation in the colorectal cancer cohort $(33.3 \%)$ was lower compared to what has been reported in the cBioportal (53.4\%) and IARC TP53 database $(43.3 \%)[15,18,19]$.

The incidence of overweight and obesity is increasing significantly worldwide, and it is associated with obesityrelated cancers, including postmenopausal BC and CRC [20]. In our study cohort $63.3 \%$ of the $\mathrm{BC}$ patients and $38.1 \%$ of the CRC patients were either overweight, preobese or obese based on Asian criteria for BMI cut-off.

\section{Variant analysis}

All the 13 variants altering proteins are found between exons 5 to 8 and 9 (69\%) of them are missense variants. It is supported by the data provided in IARC TP53 database as approximately $95 \%$ of the pathogenic variants are found between exons 5 to 8 and $73 \%$ of the alterations are missense variants. According to cosmic database, 53.14 and $52.83 \%$ of the alterations found in breast and colorectal cancers respectively are missense variants $[6,15]$.

Among the pathogenic variants found, the frameshift variants; c.848_849delGC, c.851_855delCAGAG and the 
Table 4 Correlation between p53, p21, MDM2 expression with TP53 gene status in (1) breast cancer and (2) colorectal cancer.

1)

\begin{tabular}{|c|c|c|c|c|}
\hline Patient code & $\begin{array}{c}\text { TP53 gene } \\
\text { status }\end{array}$ & $\mathrm{p} 53$ & $\mathrm{p} 21$ & MDM2 \\
\hline 31 & M & & & \\
\hline 32 & WT & & & \\
\hline 34 & WT & & & \\
\hline 37 & M & & & \\
\hline 39 & WT & & & \\
\hline 42 & WT & & & \\
\hline 43 & WT & & & \\
\hline 55 & WT & & & \\
\hline 60 & WT & & & \\
\hline 66 & WT & & & \\
\hline 82 & WT & & & \\
\hline 87 & M, S & & & \\
\hline 91 & S & & & \\
\hline
\end{tabular}

2)

\begin{tabular}{|c|c|c|c|c|}
\hline Patient code & $\begin{array}{c}\text { TP53 gene } \\
\text { status }\end{array}$ & p53 & p21 & MDM2 \\
\hline 26 & WT & & & \\
\hline 36 & WT & & & \\
\hline 45 & N & & & \\
\hline 64 & WT & & & \\
\hline 65 & M & & & \\
\hline 70 & M & & & \\
\hline 72 & WT & & & \\
\hline 75 & WT & & & \\
\hline 76 & WT & & & \\
\hline 78 & WT & & & \\
\hline 79 & S & & & \\
\hline 81 & WT & & & \\
\hline 84 & WT & & & \\
\hline 90 & M & & & \\
\hline
\end{tabular}
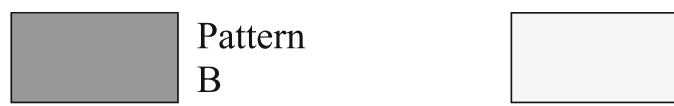

Pattern

C

in-frame variant; c.431_433delAGC have not been previously reported. The c.637C $>\mathrm{T}$, nonsense variant has been commonly reported in colon, breast, oesophageous, skin, and stomach cancers. The somatic missense variants; c. $400 \mathrm{~T}>\mathrm{G}$, c. $524 \mathrm{G}>\mathrm{A}$, c. $581 \mathrm{~T}>\mathrm{G}, \quad$ c.730G $>\mathrm{T}$, c.733G > A, c.743G > A, c.840A $>$ T and c.844C $>$ T have 
been reported in various cancers previously. However, c.730G $>\mathrm{T}$ and c.840A $>\mathrm{T}$ found in our $\mathrm{BC}$ patient cohort have been not previously reported in any type of BCs. On the other hand, c.524G > A, c.733G > A and $844 \mathrm{C}>\mathrm{T}$ found in the CRC patient cohort have been previously reported with a high prevalence in CRC cases. The likely pathogenic variant, c.626G > A, observed in our $\mathrm{BC}$ cohort also has been reported in various cancers but not in $\mathrm{BC}$. The c.63C $>\mathrm{T}$ silent variant is reported only in the IARC TP53 database and the details are not provided. The c.459C $>\mathrm{T}$ variant has been observed previously in $\mathrm{BC}$ but not in $\mathrm{CRC}$, whereas c.903A $>\mathrm{G}$ has been reported only in oesophageal and central nervous system cancers $[6,15]$.

The exonic variants c.637C > T, c.524G > A, c.844C > $\mathrm{T}$, c. $63 \mathrm{C}>\mathrm{T}, \mathrm{c} .459 \mathrm{C}>\mathrm{T}$ and c. $-140 \mathrm{G}>\mathrm{A}$ found in this study were also observed in head and neck cancer patients by us [14]. Comparison of TP53 variants found in BCs with those in CRCs in this study showed c.637C $>\mathrm{T}$ and c.-140G > A were the only two exonic variants found in common. Among the seven pathogenic TP53 variants found in CRC patients in the present cohort, only two were present in males suggesting a higher prevalence of pathogenic TP53 variation in females when compared to males in CRC, although larger number of patient samples would need to be analysed to confirm this.

The most important factors that control the regulation of normal breast cell growth are p53 and hormone receptors PR, ER and HER-2. In normal breast tissues, cell proliferation is promoted by oestrogen. Stimulation of oestrogen also increases the level of p53 by both increasing the transcription and stabilization of p53. The increased level of p53 counters enhanced cell proliferation, thus keeping the proliferation and cell death in balance. However, in the cells where the p53 and ER levels are deregulated, the equilibrium between the cell proliferation and cell death is disturbed which leads to the uncontrolled tumour growth. Similarly, even PR and HER2 have functional interactions with mutant p53 [1, 21, 22]. Studies have reported that of the tumours with TP53 mutations, $55 \%$ are ER and PR negative, and $57 \%$ to be HER2 negative [23]. According to the Multi-Omics Breast Cancer Database, all 3 patients reported with a tumour somatic c.743G > A variant had a triple negative hormone status where the $\mathrm{BC}$ patient lacks ER, PR expression as well as HER2 expression [24]. In our study, 2 out of the 3 patients detected with a c.743G > A variant were triple negative and the other patient's receptor status is unknown. In addition, a patient with a c.848_849delGC variant tumour also had triple negative $\mathrm{BC}$ diagnosed.

Analysis of KRAS, BRAF and PI3KCA genes helps in the prognosis as well as in the treatment of colorectal cancer [25]. Out of seventeen CRC patients analysed for KRAS, BRAF and PIK3CA, none of them had BRAF or
PIK3CA pathogenic hotspot variant sequences, but 4 had pathogenic variants in KRAS; three in codon 12 and one in codon 61 . Out of these 4 patients, three had pathogenic TP53 variants; one had a previous history of cervical cancer and another had a previous history of ovarian cancer.

There are controversial opinions on the association of cancer risk and prognosis with codon 72 polymorphism, as some studies suggests that codon 72 Arginine has a protective effect based on a greater apoptotic potential [26-28] while others failed to replicate these findings $[29,30]$. In the present study neither allele of p.R72P was significantly associated with BC or CRC. Similarly in our previous studies no significant association was found between the codon 72 polymorphism and head and neck cancer [14]. However, the number of patients in the current study is too small to draw definitive negative conclusions about any association with cancer risk and prognosis.

\section{Immunohistochemical analysis}

Wild type p53 has a very short half - life, as it is generally kept under tight auto-regulatory control by MDM2. But in the case of mutant p53, the p53-dependent MDM2 expression is lost and mutant forms of p53 are no longer recognised by MDM2. The breakdown of the MDM2 mediated negative feedback loop leads to the accumulation of mutant p53 [31, 32]. All 6 missense variants identified in the current study were associated with the accumulation of mutant $\mathrm{p} 53$ protein resulting in the Pattern-A IHC staining, whereas all the samples $(N=11)$ with Pattern-B IHC were TP53 wild-type. Six other wild-type samples, two samples with silent mutations and one sample with a nonsense variant showed no positive immuno-reactivity. Similar results were observed in our previous study on head and neck cancer [14]. TP53 missense mutations are strongly associated with the strong immuno positivity of p53 protein in breast ( $p$ value $=0.001417)$ and breast and colorectal cancer combined $(\mathrm{p}$-value $=8.104 \mathrm{e}-06)$. Several previous studies which observed an association between TP53 mutations and higher expression of $\mathrm{p} 53$ protein in various types of cancer $[33,34]$ also support our findings. A larger study done on 7878 variants representing 60 distinct tumour sites from the IARC TP53 Database concludes that missense mutations are IHC positive while nonsense mutations, frameshift mutations and deletions were immunonegative [35].

A number of studies have examined the relationship between the expression pattern of p53 and p 21 in various human tumours with conflicting results. Some studies showed that abnormal p53 (overexpression) was associated with low or complete absence of expression of p21 [36-38], while others showed no significant 
correlation between p21 expression and the abnormal accumulation of p53 $[39,40]$. Lack of correlation of p53 and p21 may be either due activation of p21 via p53 independent pathways or due to some p53 mutants being still able to transcriptionally turn on the $\mathrm{p} 21$ protein [37]. Another important transcriptional target of p53 is MDM2. However, there are limited number of studies focused on the association of expression between p53 and MDM2. According to those studies, higher expression of both p53 and MDM2 was observed in most of the pancreatic cancer and sarcoma cases examined [41, 42]. This overexpression of MDM2 may be due to p53independent transcriptional activation even in the presence of abnormal p53. In addition, functional studies have reported another novel mechanism of MDM2 stabilization and accumulation. MDM2 in tumour cells may be stabilized by interaction with mutant p53 and thus lead to accumulation [43]. We attempted to investigate the functional activity of p53 by analysing the expression of the downstream proteins of p53 namely, p21 and MDM2 in our study cohort. There is no significant correlation observed between TP53 gene status and p21 protein staining in breast cancer $(p$-value $=0.9214)$ and in colorectal cancer ( $p$-value $=0.6426$ ). Similarly, no significant correlation was found between TP53 gene status and MDM2 protein both in breast cancer $(\mathrm{p}$-value = 0.0522 ) and colorectal cancer ( $\mathrm{p}$-value $=0.6914$ ). According to Spearman's Rank Correlation, there are no significant correlations in the expression of p21 and MDM2 in relation to expression of $\mathrm{p} 53$. This non-consistent pattern in the expression of $\mathrm{p} 21$ and MDM2 in relation to expression of p53 and mutational status of TP53 may be due to the p53 independent pathways of p21 and MDM2 activation and the limited sample size. Thus, analysis of p21 and MDM2 protein expression in combination with $\mathrm{p} 53$ protein expression had no added advantage in differentiating between normal and mutant p53 protein.

\section{Conclusion}

We examined all exons and splicing sites of the TP53 gene in $\mathrm{BC}$ and CRC in a cohort of Sri Lankan patients and found a high occurrence of gene alterations including several novel variants. All p53 protein altering variants found were positioned between exons 5-8. Only the point missense variants were associated with strong immuno-positive staining for p53. TP53 wild type samples were associated with either rare isolated positively staining cells on tumour sections or complete absence of positive signal. Both truncating and silent variants were associated with the absence of positive IHC staining for p53. However there was no significant correlation found between the expression of p21 and MDM2 with the expression of $\mathrm{p} 53$.

\section{Supplementary information}

Supplementary information accompanies this paper at https://doi.org/10. 1186/s12885-020-6573-5.

Additional file 1: Table S1. Optimised concentration, incubation time of the primary antibodies and antigen retrieval buffer

Additional file 2: Table S2. In-silico and functional prediction of identified variants

\section{Abbreviations}

BC: Breast cancer; CRC: Colorectal cancer; ER: Estrogen Receptor; FFPE: Formalin Fixed Paraffin Embedded; HER2: Human Epidermal growth factor Receptor-2; IHC: Immunoistochemistry; PCR: Polymerase Chain Reaction; PR: Progesterone Receptors

\section{Acknowledgements}

The authors are very grateful to the Director and staff of the National Cancer Institute, Maharagama, Sri Lanka, all patients and healthy controls who agreed to participate in this study, Ms. Joanne Kotelawela, Ms. Tharmini Sundralingam in the collection of healthy controls, Ms. Anoma Jayasoma senior technical officer, Ms. Chameera Helani - library information assistant, Ms. Tharini Somaratna - technical officer and other staff of the Institute of Biochemistry, Molecular Biology and Biotechnology, University of Colombo; Ms.Gayani Kokila Wijesinghe, Ms. Yamuna Wickramasinghe Jayasekera - Staff technical officer of Department of Pathology, Faculty of Medicine, University of Colombo, Sri Lanka, Dr. Calum Kirk - research technician of Northern Institute for Cancer Research, Newcastle University for various assistance.

\section{Authors' contributions}

VM performed experiments, contributed to the analysis, interpretation of the data, and drafted the manuscript. EHK, KHT and SDS conceived and designed the study, helped molecular genetic studies, data analysis and interpretation and revision of the manuscript. KDS and PA provided clinical expertise, recruitment of study participants, supervised clinical data and histopathological characterization. SV provided expertise in statistical analysis of data, interpretation and revision of the manuscript. $J$ provided expertise in immunohistochemical studies, discussion of sequencing data and revision of the manuscript. All authors have read and approved the final version of the manuscript.

\section{Funding}

This study was funded by National Research Council, Sri Lanka (grant number 15-33) and Commonwealth Scholarship Commission of the UK (grant number LKCN-2015-100). These funding bodies had no role in the design of the study, collection, analysis, and interpretation of data and in writing the manuscript.

\section{Availability of data and materials}

The datasets used and/or analysed during the current study are available from the corresponding author on reasonable request.

\section{Ethics approval and consent to participate}

The present study was approved by the Ethics Review Committee, Faculty of Medicine, University of Colombo, Sri Lanka (EC/14/160). Written informed consent form at the time of enrolment was obtained from each patient.

\section{Consent for publication}

Not applicable.

\section{Competing interests}

The authors declare that they have no competing interests.

\section{Author details}

${ }^{1}$ Institute of Biochemistry Molecular Biology and Biotechnology, University of Colombo, 90, Cumaratunga Munidasa Mawatha, Colombo 3, Sri Lanka. ${ }^{2}$ National Cancer Institute, Maharagama, Sri Lanka. ${ }^{3}$ Department of Pathology, Faculty of Medicine, University of Colombo, 25 Kynsey Road, Colombo 8, Sri Lanka. ${ }^{4}$ Department of Statistics, Faculty of Science, University of Colombo, Colombo 3, Sri Lanka. ${ }^{5}$ Northern Institute for Cancer Research, 
Newcastle University, Paul O'Gorman Building, Framlington Place, Newcastle upon Tyne NE2 4AD, UK

Received: 8 July 2019 Accepted: 23 January 2020

Published online: 30 January 2020

\section{References}

1. Walerych D, Napoli M, Collavin L, Del Sal G. The rebel angel: mutant p53 as the driving oncogene in breast cancer. Carcinogenesis 2012;33:11. https:// doi.org/https://doi.org/10.1093/carcin/bgs232.

2. Arnold M, Sierra MS, Laversanne M, Soerjomataram I, Jemal A, Bray F. Global patterns and trends in colorectal cancer incidence and mortality. Gut. 2017; 66:4. https://doi.org/https://doi.org/10.1136/gutjnl-2015-310912.

3. Cancer Incidence Data, Sri Lanka 2010. In Edited by Programme NCC Sri Lanka.

4. BREAST CANCER.ORG. https://www.breastcancer.org/

5. Haggar FA, Boushey RP. Colorectal cancer epidemiology: incidence, mortality, survival, and risk factors. Clin Colon Rectal Surg 2009;22:04. https:// doi.org/https://doi.org/10.1055/s-0029-1242458.

6. Tate JG, Bamford S, Jubb HC, Sondka Z, Beare DM, Bindal N, et al. COSMIC: the catalogue of somatic mutations in Cancer. Nucleic Acids Res 2018. https://doi.org/https://doi.org/10.1093/nar/gky1015.

7. The TP53 website. 2017. https://p53.fr/.

8. Kandioler-Eckersberger D, Ludwig C, Rudas M, Kappel S, Janschek E, Wenzel $C$, et al. TP53 mutation and p53 overexpression for prediction of response to neoadjuvant treatment in breast cancer patients. Clin Cancer Res. 2000;6:1.

9. Olivier M, Hainaut P. TP53 mutation patterns in breast cancers: searching for clues of environmental carcinogenesis. In: Semin Cancer Biol: 2001: Elsevier; 2001: 353-60. https://doi.org/10.1006/scbi.2001.0390.

10. Hill KA, Sommer SS. p53 as a mutagen test in breast cancer. Environ Mol Mutagen 2002;39:2-3. http://dx.doi.org/https://doi.org/10.1002/em.10065.

11. Lu Y, Segelman J, Nordgren A, Lindström L, Frisell J, Martling A. Increased risk of colorectal cancer in patients diagnosed with breast cancer in women. Cancer Epidemiol 2016;41. https://doi.org/https://doi.org/10.1016/j. canep.2016.01.006

12. Andersson M, Jensen M-B, Engholm G, Henrik Storm H. Risk of second primary cancer among patients with early operable breast cancer registered or randomised in Danish breast Cancer cooperative group (DBCG) protocols of the 77, 82 and 89 programmes during 1977-2001. Acta Oncol 2008;47:4. https://doi.org/https://doi.org/10.1080/02841860801978921.

13. Tang L, Nugent Z, Demers A, Singh $H$. Incidence of right-sided colorectal cancer after breast cancer: a population-based study. Am J Gastroenterol 2009;104:5. https://doi.org/https://doi.org/10.1038/ajg.2009.32.

14. Manoharan V, Karunanayake EH, Tennekoon KH, De Silva S, De Silva K, Angunawela P, Lunec J. Nucleotide variants and protein expression of TP53 in a Sri Lankan cohort of patients with head and neck cancer. Mol Med Report 2019;19:2781-2791. https://doi.org/https://doi.org/10.3892/mmr.2019. 9948.

15. Bouaoun L, Sonkin D, Ardin M, Hollstein M, Byrnes G, Zavadil J, et al. TP53 variations in human cancers: new lessons from the IARC TP53 database and genomics data. Hum Mutat 2016;37:9. https://doi.org/https://doi.org/10. 1002/humu.23035

16. Richards S, Aziz N, Bale S, Bick D, Das S, Gastier-Foster J, et al. Standards and guidelines for the interpretation of sequence variants: a joint consensus recommendation of the American College of Medical Genetics and Genomics and the Association for Molecular Pathology. Genet Med 2015;17: 5. https://doi.org/https://doi.org/10.1038/gim.2015.30.

17. Rosen P. Invasive Mammary Carcinoma In: Edited by Harris JR LM, Morrow M, Hellman S. Diseases of the Breast. Lippincott-Raven Philadelphia, PA; 1996. 393-420. https://doi.org/https://doi.org/10.1002/bjs.1800831157.

18. Cerami E, Gao J, Dogrusoz U, Gross BE, Sumer SO, Aksoy BA, et al. The cBio Cancer genomics portal: an open platform for exploring multidimensional Cancer genomics Data. Cancer Discov 2012;2:5. https://doi.org/https://doi. org/10.1158/2159-8290.CD-12-0095

19. Gao J, Aksoy BA, Dogrusoz U, Dresdner G, Gross B, Sumer SO, et al. Integrative analysis of complex cancer genomics and clinical profiles using the cBioPortal. Sci Signal 2013;6:269. https://doi.org/https://doi.org/10.1126/ scisignal.2004088.

20. Berger NA. Obesity and cancer pathogenesis. Ann N Y Acad Sci 2014;1311:1. https://dx.doi.org/10.1111\%2Fnyas.12416.
21. Berger C, Qian Y, Chen X. The p53-estrogen receptor loop in cancer. Curr Mol Med 2013;13:8. https://doi.org/https://doi.org/10.2174/ 15665240113139990065

22. Casalini P, Botta L, Ménard S. Role of p53 in HER2-induced proliferation or apoptosis. J Biol Chem 2001;276:15. https://doi.org/https://doi.org/10.1074/ jbc.M009732200.

23. Pereira B, Chin S-F, Rueda OM, Vollan H-KM, Provenzano E, Bardwell HA, et al. The somatic mutation profiles of 2,433 breast cancers refine their genomic and transcriptomic landscapes. Nat Commun 2016;7. https://doi. org/https://doi.org/10.1038/ncomms11479.

24. Xie B, Yuan Z, Yang Y, Sun Z, Zhou S, Fang X. MOBCdb: a comprehensive database integrating multi-omics data on breast cancer for precision medicine. Breast Cancer Res Treat 2018;169:3. https://doi.org/https://doi.org/ 10.1007/s10549-018-4708-Z

25. Zhao B, Wang L, Qiu H, Zhang M, Sun L, Peng P, et al. Mechanisms of resistance to anti-EGFR therapy in colorectal cancer. Oncotarget. 2017;8:3. https://doi.org/https://doi.org/10.18632/oncotarget.14012.

26. Dumont P, Leu JIJ, Della Pietra AC, George DL, murphy M. The codon 72 polymorphic variants of p53 have markedly different apoptotic potential. Nat Genet 2003;33. https://doi.org/https://doi.org/10.1038/ng1093.

27. Toyama T, Zhang Z, Nishio M, Hamaguchi M, Kondo N, Iwase H, et al. Association of TP53 codon 72 polymorphism and the outcome of adjuvant therapy in breast cancer patients. Breast Cancer Res 2007:9:3. https://doi. org/https://doi.org/10.1186/bcr1682.

28. Damin AP, Frazzon AP, Damin DC, Roehe A, Hermes V, Zettler C, et al. Evidence for an association of TP53 codon 72 polymorphism with breast cancer risk. Cancer Detect Prev 2006;30:6. https://doi.org/https://doi.org/10. 1016/j.cdp.2006.09.007

29. Baynes C, Healey CS, Pooley KA, Scollen S, Luben RN, Thompson DJ, et al. Common variants in the ATM, BRCA1, BRCA2, CHEK2 and TP53 cancer susceptibility genes are unlikely to increase breast cancer risk. Breast Cancer Res 2007;9:2. https://doi.org/https://doi.org/10.1186/bcr1669.

30. Mabrouk I, Baccouche S, El-Abed R, Mokdad-Gargouri R, Mosbah A, Sal̈d S, et al. No evidence of correlation between p53 codon 72 polymorphism and risk of bladder or breast carcinoma in Tunisian patients. Ann N Y Acad Sci 2003:1010:1. https://doi.org/https://doi.org/10.1196/annals.1299.137.

31. Reich NC, Oren $M$, Levine A. Two distinct mechanisms regulate the levels of a cellular tumor antigen, p53. Mol Cell Biol 1983;3:12. https://doi.org/https:// doi.org/10.1128/mcb.3.12.2143.

32. Blagosklonny MV. Loss of function and p53 protein stabilization. Oncogene. 1997;15:16. https://doi.org/https://doi.org/10.1038/sj.onc.1201374.

33. Liu J, Li W, Deng M, Liu D, Ma Q, Feng X. Immunohistochemical determination of p53 protein overexpression for predicting p53 gene mutations in hepatocellular carcinoma: a meta-analysis. PLoS One 2016; 11(7):e0159636. https://doi.org/https://doi.org/10.1371/journal.pone.0159636.

34. Liu Z, Jiang Z, Gao Y, Wang L, Chen C, Wang X. TP53 mutations promote immunogenic activity in breast cancer. J Oncol 2019;2019. https://doi.org/ https://doi.org/10.1155/2019/5952836.

35. Murnyák B, Hortobágyi T. Immunohistochemical correlates of TP53 somatic mutations in cancer. Oncotarget. 2016;7(40):64910. https://doi.org/https:// doi.org/10.18632/oncotarget.11912.

36. Doglioni C, Pelosio P, Laurino L, Macri E, Meggiolaro E, Favretti F, et al. p21/ WAF1/CIP1 expression in normal mucosa and in adenomas and adenocarcinomas of the colon: its relationship with differentiation. J Pathol 1996;179:3. https://doi.org/10.1002/(SICI)1096-9896(199607)179:3\%3C248:: AID-PATH571\%3E3.0.CO;2-6.

37. Bukholm I, Nesland J, Karesen R, Jacobsen U, Børresen A. Relationship between abnormal p53 protein and failure to express p21 protein in human breast carcinomas. J Pathol 1997;181:2. https://doi.org/10.1002/(SICI)10969896(199702)181:2\%3C140::AID-PATH745\%3E3.0.CO;2-A.

38. Thor AD, Liu S, Moore li DH, Shi Q, Edgerton SM. p21 WAF1/CIP1 expression in breast cancers: associations with p53 and outcome. Breast Cancer Res Treat 2000;61:1. https://doi.org/https://doi.org/10.1023/a:1006455526894.

39. Yasui W, Akama Y, Yokozaki H, Semba S, Kudo Y, Shimamoto F, et al. Expression of p21WAF1/CIP1 in colorectal adenomas and adenocarcinomas and its correlation with p53 protein expression. Pathol Int 1997;47:7. https:// doi.org/https://doi.org/10.1111/j.1440-1827.1997.tb04526.x.

40. Marchetti A, Doglioni C, Barbareschi M, Buttitta F, Pellegrini S, Bertacca G, et al. p21 RNA and protein expression in non-small cell lung carcinomas: evidence of p53-independent expression and association with tumoral differentiation. Oncogene. 1996;12:6. 
41. Dong M, Ma G, Tu W, Guo K-J, Tian Y-L, Dong Y-T. Clinicopathological significance of p53 and $\mathrm{mdm} 2$ protein expression in human pancreatic cancer. World J Gastroenterol 2005;11:14. https://doi.org/https://doi.org/10, 3748/wjg.v11.i14.2162.

42. Arici A, Ozgur T, Ugras N, Yalcinkaya U. Immunohistochemical detection of p53 and MDM2 expressions in liposarcoma with world health organization classification. Indian J Cancer 2013;50:3. https://doi.org/https://doi.org/10. 4103/0019-509X.118717.

43. Peng Y, Chen L, Li C, Lu W, Agrawal S, Chen J. Stabilization of the MDM2 oncoprotein by mutant p53. J Biol Chem 2001;276:9. https://doi.org/https:// doi.org/10.1074/jbc.C000781200.

\section{Publisher's Note}

Springer Nature remains neutral with regard to jurisdictional claims in published maps and institutional affiliations.

Ready to submit your research? Choose BMC and benefit from:

- fast, convenient online submission

- thorough peer review by experienced researchers in your field

- rapid publication on acceptance

- support for research data, including large and complex data types

- gold Open Access which fosters wider collaboration and increased citations

- maximum visibility for your research: over $100 \mathrm{M}$ website views per year

At BMC, research is always in progress.

Learn more biomedcentral.com/submissions 